\title{
Studies on the Accumulation of Drought-Induced Boiling Soluble Proteins (Hydrophilins) at Vegetative and Reproductive Phases of Drought Tolerant and Susceptible Cultivars of Triticum aestivum
}

\author{
Gurmeen RAKHRA ${ }^{1}$, Arun Dev SHARMA ${ }^{1 *}$, Jatinder SINGH ${ }^{2}$ \\ ${ }^{1}$ P.G. ,Department of Biotechnology, Lyallpur Khalsa College, GT Road, Jallandhar-144001, Punjab, India; arundevsharma@hotmail.com \\ (*orrespondingauthor) \\ ${ }^{2}$ Guru Nanak Dev University, Department of Molecular Biology and Biochemistry, -144001, Amritsar, India
}

\begin{abstract}
Drought is one of the major environmental constraints affecting the crops worldwide. Expression of boiling soluble proteins (BSPs) is of paramount importance, because they play important roles in the water stress responses and also in plant metabolism. In this study, the effect of drought on BSPs at vegetative (shoots) and reproductive (seeds) phases of drought tolerant (cv. 'PBW 527') and drought susceptible (cv. 'PBW 343') cultivars of Triticum aestivum were carried at three different developmental stages. The boiling soluble protein profiles of shoots and seeds were outlined via SDS-PAGE followed by immune-blot analysis using anti-HSP, anti-APase, anti-LEA, anti-SOD, anti-AQUA and anti-CAT antibodies. Western blot analysis revealed that expression of BSPs was modulated differentially in a stress, tissue, developmental stage and cultivar dependent manner. For instance, enhanced expression of seeds BSPs (APase, LEA, CAT, AQUA) was observed in the tolerant cv. 'PBW 527' after drought stress. However, no such enhancement was observed in the susceptible cultivar. Similarly, in shoots of cv. 'PBW 527', a substantial increase of BSP (SOD) expression was established after drought stress treatment, indicating their role in drought stress adaptation. Further, to gain an insight into the role of BSPs, a time course pre- and post-stress kinetic studies were also conducted in the seeds of tolerant and susceptible wheat cultivars. Based upon the observations, the possible role of boiling soluble proteins (hydrophilins) in water stress tolerance is discussed.
\end{abstract}

Keywords: APase, AQUA, boiling soluble proteins, CAT, LEA, wheat

\section{Introduction}

Growth and productivity of various cereals are affected by a plethora of abiotic factors, out of which drought is one of the most limiting factors occurring frequently. It is defined as a decrease in soil water potential resulting in reduced osmotic potential by plants for the water absorption by the congestion of soluble carbohydrates, proline and other osmolytes (Chaves et al., 2003; Atkinson et al., 2013). Drought affects the yield, productivity, growth, reproductive efficacy of the crop at different stages more than any other environmental stress (Zhu, 2002). According to Pfeiffer et al. (2005), 50\% of wheat production area is affected due to drought worldwide.

Due to their static nature, plants have evolved drought avoidance and drought tolerance mechanisms to cope up with the environmental stresses. Drought avoidance is achieved through morphological changes in the plant like extensive and branched root system, stomatal conductance and decreased leaf area. Drought tolerance is accomplished through specific gene expression and accumulation of specific proteins. The genes whose expression is modified can be studied under three categories (i) those playing roles in the signalling cascades and in transcriptional control, such as MAP kinases and SOS kinase and transcriptional factors such as $\mathrm{HSF}, \mathrm{CBF} / \mathrm{DREB}$, and $\mathrm{ABF} / \mathrm{ABAE}$ families (ii) those functioning directly in the maintenance, stabilization, protection of membranes and proteins, such as heat shock proteins (Hsps), chaperones, late embryogenesis abundant (LEA) proteins, osmoprotectants and free-radical scavengers (iii) those playing roles in water, ion uptake and transport such as aquaporins and ion transporters (Ingram and Bartels 1996; Bray, 2004; Shinozaki and YamaguchiShinozaki, 2007). Among all stress induced proteins, dehydrins/LEA, HSPs, antioxidants like SOD and CAT are the major groups of stress induced proteins which are believed to provide cellular protection during water stress (Chaves et al., 2003). Quantitative and qualitative changes in the expression of these proteins in response to water stress have been reported earlier (Shinozaki and Yamaguchi- 
226

Shinozaki, 2007). These proteins are also produced in response to various other environmental stresses such as salt and cold. Over expression analysis of some water stress proteins (LEAs) revealed enhanced dehydration, salt and cold tolerance in plants indicating their role in water stress adaptation (Bray, 2004).

Besides, being stress responsive, some water stress induced proteins (e.g. LEA, HSP) are highly hydrophilic and remain stable and soluble even after $10 \mathrm{~min}$ of boiling (Neven et al., 1993; Garay Arroyo et al., 2000), a characteristic that has been termed as boiling soluble proteins. Previously, Pelah et al. (1995) also observed that even some of the proteins detected in total protein extracts, under drought stress, are lost after boiling in the treated extracts. A detailed and comprehensive picture regarding the functions of these boiling soluble proteins remains elusive. Hence, to better elucidate the role of these boiling soluble proteins (BSPs)/ hydrophilins under drought stress, it is important to examine their protein expression not only under water stress, but also after boiling. It has been suggested that they might be participating in membrane protein stability, osmotic adjustment, desiccation tolerance in seeds, binding ions accumulated under stress and stabilization of unfolded proteins (Chaves et al., 2003). Close (1996) hypothesized that hydrophilic regions of dehydrins in the presence of compatible solutes drives the partially unfolded proteins back to folded state thereby preventing denaturation under water limiting conditions.

During past decades, developing drought resistant cultivars by understanding the tolerance mechanism of water stress responsive proteins encoding genes has been the objective for the plant breeders. Most of these proteins represent a diverse group of distinct proteins. However, the drought tolerance studies are still a matter of conjuncture owing to the environmental interactions, complex phenotype, multigenic nature and the quantitative trait (Zhu, 2002). The complexity is due to some factors like plant variety, species, the dynamics, duration, intensity of stress and the phenological state in which water deficit is developed. Hence, in order to find out the role of BSPs in drought stress adaptation, it is imperative that expression profile of BSPs should be studied in stress susceptible and tolerant cultivars of a crop. In the continuation of our previous study (Sharma et al., 2012), the present study was conducted in two different cultivars of wheat: 'PBW 527' (tolerant), 'PBW 343' (susceptible) so as to characterize their response to drought at protein level at different stages of their development. The assessment and expression analysis of BSPs observed in this study under drought stress could unravel the underlying mechanisms of drought tolerance and possible implication of BSPs as a biochemical marker for water stress adaptation. Our results can suggest possible targets for the enhancement of drought tolerance in wheat by manipulating the expression of the boiling stable proteins. Among various crops, wheat is one of the most important crops of arid and semi- arid areas worldwide and is sensitive to drought and temperature stress. Hence, we have selected wheat as an important crop for the present investigation. For the detection of BSPs, we focused on boiling soluble fractions of the protein extracts that resists coagulation upon heating at $100{ }^{\circ} \mathrm{C}$ and are devoid of storage proteins.

\section{Materials and methods}

\section{Growth and Stress conditions}

The seeds of Triticum aestivum L. cvs. 'PBW 527' (drought tolerant) and 'PBW 343' (drought sensitive) differing in degree of drought tolerance (Sharma et al., 2014) were procured from PAU Ludhiana, Punjab, India. The seeds were surface sterilized with $1 \%(\mathrm{w} / \mathrm{v})$ mercuric chloride and $70 \%$ ethanol. Plants of the two cultivars were raised in $5 \mathrm{~L}$ pots and kept in a net house under natural conditions. Shoots at vegetative phase $\{30,57$ and 90 Days Post Sowing (DPS) $\}$ and seeds at reproductive phase $\{30,60$ and 90 Days Post Anthesis (DPA) $\}$ were harvested in triplicates, pooled and used for further analysis. Individual earheads were tagged on the day of anthesis. Water stress was imposed by withholding water for consecutive 5-6 days while the control plants were watered daily. Relative Water Content (RWC) was calculated as per equation $=(\mathrm{FW}$ DW/TW-DW) X 100. Fresh tissues (shoots/seeds) were weighed to obtain the fresh weight (FW).The tissues were then kept in water for 2 hrs to get the turgid weight (TW). For dry weight (DW), tissues were dried at $72{ }^{\circ} \mathrm{C}$ for $72 \mathrm{hrs}$ till constant weight was achieved.

\section{Extraction of boiling soluble proteins}

The boiling soluble proteins were extracted as described previously (Sharma et al., 2012). The total soluble protein content was determined using BSA as a standard according to Lowry et al. (1951). Protein samples were resolved on SDS-PAGE on $10 \%(\mathrm{w} / \mathrm{v})$ polyacryalamide gel and visualized by Coomassie brilliant blue as described in Sambrook et al. (1989).

\section{Estimation of total Chlorophyll and Chl a/b contents}

The total Chlorophyll and its different fractions were estimated from the harvested samples under control and drought conditions according to Arnon 1949. Fresh leaf samples were crushed thoroughly with $80 \%$ acetone and centrifuged at $10,000-\mathrm{g}$ for $10 \mathrm{~min}$ at $4{ }^{\circ} \mathrm{C}$. The absorbance of the supernatant was read at 645 and $663 \mathrm{~nm}$ with a double beam UV-VIS spectrophotometer (Systronics, Model no. 2202). The following equations were used for the determination of $C h l a, C h l b$ and total Chlorophyll contents, respectively.

$$
\begin{aligned}
& C h l a(\mu \mathrm{g} / \mathrm{ml})=12.7\left(\mathrm{~A}_{663}\right)-2.69\left(\mathrm{~A}_{645}\right) \\
& C h l b(\mu \mathrm{g} / \mathrm{ml})=22.9\left(\mathrm{~A}_{645}\right)-4.68\left(\mathrm{~A}_{663}\right) \\
& \text { Total Chl }(\mu \mathrm{g} / \mathrm{ml})=20.2\left(\mathrm{~A}_{645}\right)+8.02\left(\mathrm{~A}_{663}\right)
\end{aligned}
$$

\section{Sugar estimation}

3,5-Dinitrosalicyclic acid (DNS) method was used for the estimation of the reducing sugars in the shoot samples according to Miller (1972).

\section{Western blot analysis}

Western blot analysis was carried according to Rakhra and Sharma 2013. Boiling soluble proteins (BSPs) resolved on $10 \%$ SDS-PAGE were transferred onto the nitrocellulose membranes (Hybond-C, GE Healthcare, $\mathrm{UK}$ ) using semidry Western blot system (GE healthcare). The membrane containing BSPs was blocked for $30 \mathrm{~min}$ in TBS (200 mM Tris, $1.4 \mathrm{M} \mathrm{NaCl}$ ) with $5 \%(\mathrm{w} / \mathrm{v})$ 
reconstituted dry milk. This was followed by incubation for $2 \mathrm{hrs}$ with antibodies against SOD (Superoxide dismutase, Calibiochem, USA), AQP (Aquaporin, Calbiochem, USA), HSP90 (heat shock protein $90 \mathrm{kDa}$, Calibiochem, USA), APase (Acid phosphatase), a gift from Dr. Carrol P Vance, for details kindly see Miller et al. (2001), PvLEA 18 (group 6 LEA protein, a gift from Dr AAC Robles, for details kindly see Colmenero Flores et al., 1999) and CAT (Catalase, Calibiochem, USA). Blots were given two washings of $5 \mathrm{~min}$ each with TBST (200 mM Tris, $1.4 \mathrm{M}$ $\mathrm{NaCl}$, Tween 20) and were then incubated with Alkaline phosphatase (ALP) conjugated secondary antibody (1:500 dilution) for $45 \mathrm{~min}$ and developed using 5-bromo-4chloro-3-indolyl phosphate $p$-toluidine salt/- $p$-nitroblue tetrazolium chloride reagent systems as described in Sambrook et al. (1989). Relative band intensities of immune-reactive signals were determined using densitometry analysis by Gel Visualization, Documentation and Analysis system (Bio-Rad, USA).

\section{Kinetic studies}

A time-course study was conducted between 40 and 60 DPA. Stress was imposed by withholding water at 47 DPA for consecutive ten days. Harvesting was done on $3^{\text {rd }}, 6^{\text {th }}$ and $10^{\text {th }}$ day under stress and control conditions. Post-stress kinetic study for three consecutive days was carried by relieving drought stress after the $10^{\text {th }}$ day of stress imposition. Boiling soluble protein extracts, as obtained above, were stored at $-20^{\circ} \mathrm{C}$ and used for further analysis.

\section{Statistical analysis}

The plants were distributed over a completely randomized design, with 12 treatment combinations, forming a $2 \times 2 \times 3$ factorial (two genotypes, two watering regimes and three samplings) at vegetative and reproductive phases. All results are presented as mean of three replicates \pm SD (Standard deviation). Data was subjected to student's ttest for differences between pairs of data. Means that showed significant difference at $\mathrm{P} \leq 0.05$ were considered.

\section{Results}

\section{Biochemical changes in shoots and seeds}

The results in the present study revealed that at 30 DPS, in the cv. 'PBW 343', as compared to control, total chlorophyll content decreased significantly under drought stress due to significant decline in $C h l b$ while in the other cv. 'PBW 527', no significant change in total chlorophyll content and its different fractions $(\mathrm{Chl} \mathrm{a/b})$ was observed under drought stress (Fig. 1A). Similarly, at 57 DPS, in susceptible cv. 'PBW 343', total chlorophyll content decreased significantly under drought which may be due to significant reduction in both $C h l a$ and $C h l b$ contents (Fig. 1B). On the other hand, like at 30 DPS, cv. 'PBW 527' didn't have any significant reduction in total chlorophyll content and its different fractions $(\mathrm{Chl} \mathrm{a} / \mathrm{b})$ at $57 \mathrm{DPS}$ under drought stress conditions. At 90 DPS, in cv. 'PBW 343', as compared to control, total chlorophyll content decreased considerably under drought which may be due to reduction in $C b l b$ fraction. When compared to control, total chlorophyll content in the cv. 'PBW 527' under

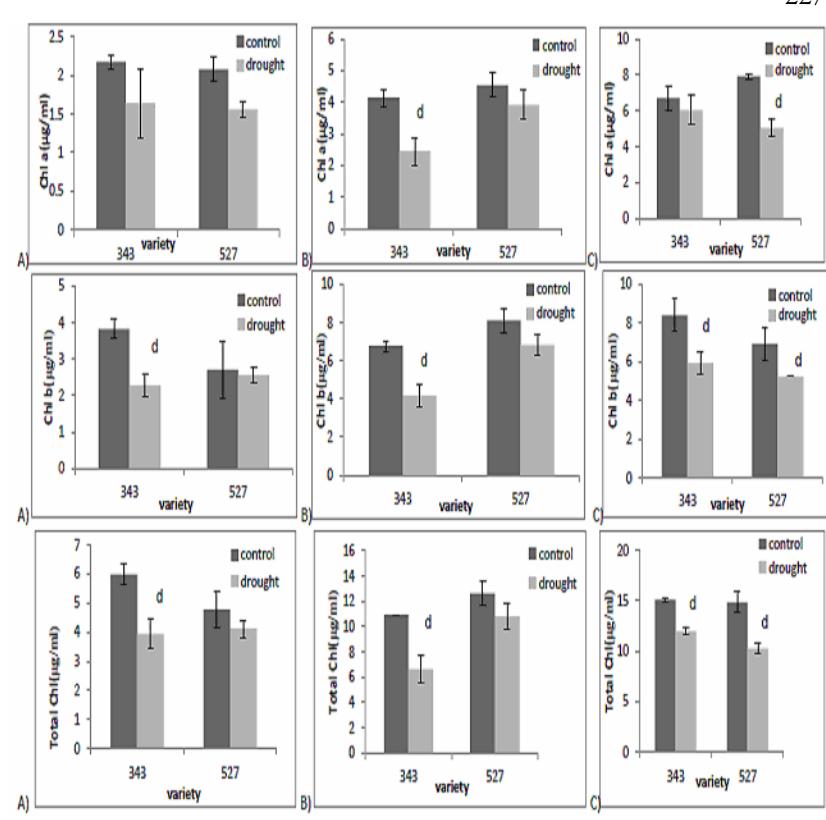

Fig. 1. Chlorophyll a (Chl a), Chlorophyll b (Chl b) and total chlorophyll content in shoots of drought tolerant ('PBW $527^{\prime}$ ') and drought sensitive ('PBW 343') cultivars of Triticum aestivum harvested at three different stages: 30 DPS (A), 57 DPS(B) and 90 DPS(C) under control and drought conditions. DPS: Days Post Sowing. Data shown are Mean $\pm S D$ of three replicates; ${ }^{d}$ indicates significant difference vs. control at $\mathrm{P} \leq 0.05$

drought decreased significantly due to significant decrease in both Chl $a$ and $C h l b$ (Fig. 1C).

Imposition of drought stress resulted in either decrease or no change in RWC of shoots in the two cultivars at their different stages. At 30 and 90 DPS, differences in RWC under drought are non-significant in both the cultivars when compared with their respective controls (Fig. 2 A, B). However, a significant decrease in RWC upon imposition of drought stress was observed at 57 DPS in susceptible cv. 'PBW 343' while tolerant cv. 'PBW 527' didn't show much variation under drought and control conditions (Fig. 2 A, B). In seeds, as compared to control, in cv. PBW 343 , RWC decreased substantially under stress at 40 DPA while no change was observed at 30 DPA and 60 DPA (Fig. 2C). In cv. 'PBW 527', RWC was unaffected by water stress as compared to the control conditions at all the developmental stages (Fig. 2D).

\section{Changes in the expression of BSPs in seeds and shoots}

Fig. 3 shows the protein profile of shoots of drought tolerant cv. 'PBW 527' and drought susceptible cv. 'PBW $343^{\prime}$ at different stages. After boiling for $15 \mathrm{~min}$, no substantial boiling soluble proteins were observed in shoots at 30 and 90 DPS (Fig. 3A). However, some barely detectable protein bands were observed at 57 DPS in both the cultivars under drought as well as control conditions (Fig. 3B). Therefore, this vegetative phase (57 DPS) was selected for further studies. Similarly like shoots, in seeds, after boiling treatment of $15 \mathrm{~min}$, many protein bands disappeared and a few barely detectable protein bands were 


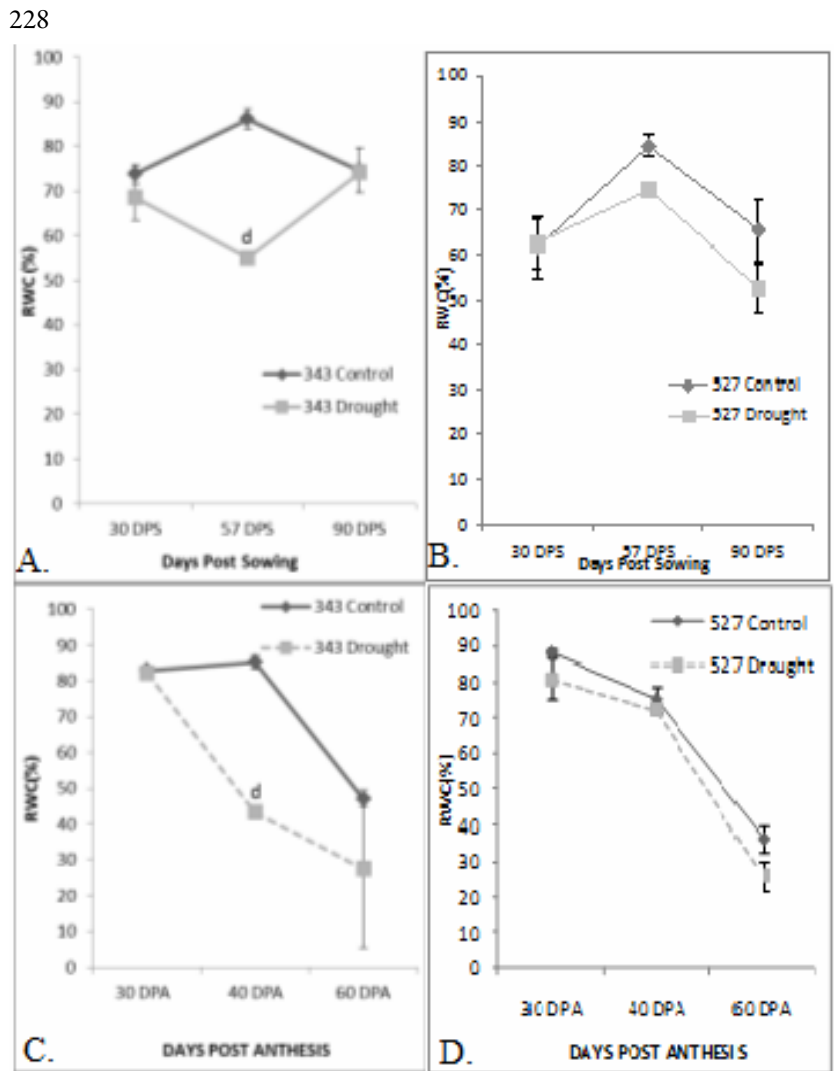

Fig. 2 : Relative Water Content (RWC) in shoots (A, B) and seeds (C, D) of drought sensitive cv. 'PBW 343' (A, C) and drought tolerant cv. 'PBW 527' (B, D) cultivars of $T$. aestivum harvested at three different vegetative and reproductive stages : 30 DPS , 57 DPS, 90 DPS and 30 DPA, 40 DPA and 60 DPA respectively under control and drought conditions. DPS: Days Post Sowing. DPA: Days Post Anthesis. Data shown are Mean $\pm S D$ of three replicates; ${ }^{d}$ indicates significant difference vs. control at $\mathrm{P} \leq 0.05$

seen at all the stages (Fig. 3B). Further, it can be seen that in both the cultivars, as compared to shoots, seeds exhibited a more number of high mol wt and low mol wt boiling soluble proteins. Quantitative differences in the synthesis of proteins between the two cultivars were further analysed by immune-blot analysis in shoots at 57 DPS and in seeds at 30,40 and 60 DPA.

\section{Changes in BsAPase}

At vegetative phase, a sharp band of $66 \mathrm{kDa}$ (BsAPase) was observed in both the cultivars under control conditions. The expression of BsAPase $(66 \mathrm{kDa})$ decreased under drought conditions in both the cultivars, with a greater decrease in the cv. 'PBW 343' (Fig. 4). At reproductive phase, western blot analysis of seeds recognized a protein band of $61 \mathrm{kDa}$ (BsAPase61) which was constitutively expressed at all the three stages (30, 40 and 60 DPA) in both the cultivars under control and stress conditions. In the tolerant cv. 'PBW 527', at 40 and 60 DPA, a remarkable increase in BsAPase61 was observed under drought stress conditions. However, in the susceptible cv. 'PBW 343' at 40 and 60 DPA, considerable decrease in BsAPase61 expression was observed under stress conditions (Fig. 5).

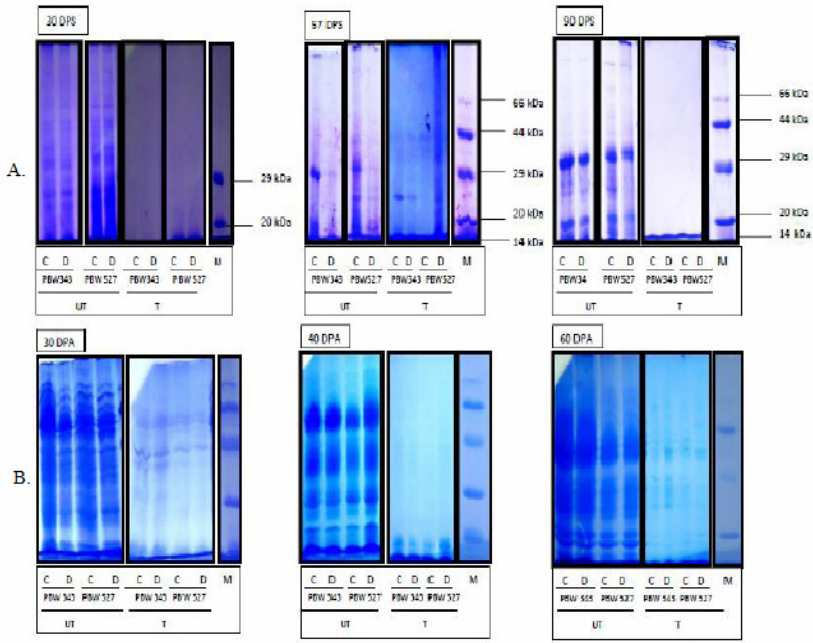

Fig. 3. An SDS PAGE profile of proteins in shoots (A) and seeds (B) of drought tolerant (PBW 527) and drought sensitive (PBW 343) cultivars of $T$. aestivum harvested at three different vegetative and reproductive stages : 30 DPS, 57 DPS, 90 DPS and 30 DPA, 40 DPA and 60 DPA respectively under control (C) and drought (D) conditions Each lane loaded with $60 \mu \mathrm{g}$ of protein sample. DPS: Days Post Sowing. DPA: Days Post Anthesis. M: Molecular weight marker. UT- Untreated / Unboiled protein samples, T-Treated/Boiled protein samples.
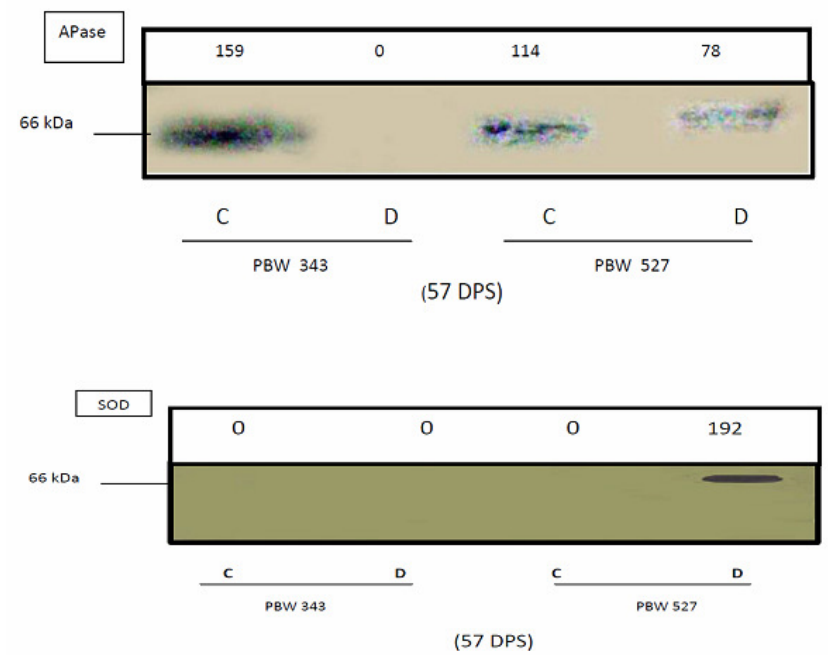

Fig. 4: Immuno-blot analysis of boiling soluble proteins in shoots of drought tolerant ('PBW 527') and drought sensitive ('PBW 343') cultivars of $T$. aestivum at three different stages (30, 57, 90 DPS) under control (C) and drought (D) conditions. Numerical values as shown in the top of panels indicates relative band intensities which were determined using Gel visualisation, Documentation and Analysis system (Bio Rad,USA).

\section{Changes in BsHSP}

In shoots, no immune-reactive band against HSP90 was observed. However in seeds, western blot analysis using anti HSP 90 monoclonal antibody in seeds recognized sharp protein band of $\mathrm{Mr} 41(\mathrm{BsHSP} 41)$ at $60 \mathrm{DPA}$ in both the cultivars under control conditions (Fig. 5). However, in cv. 

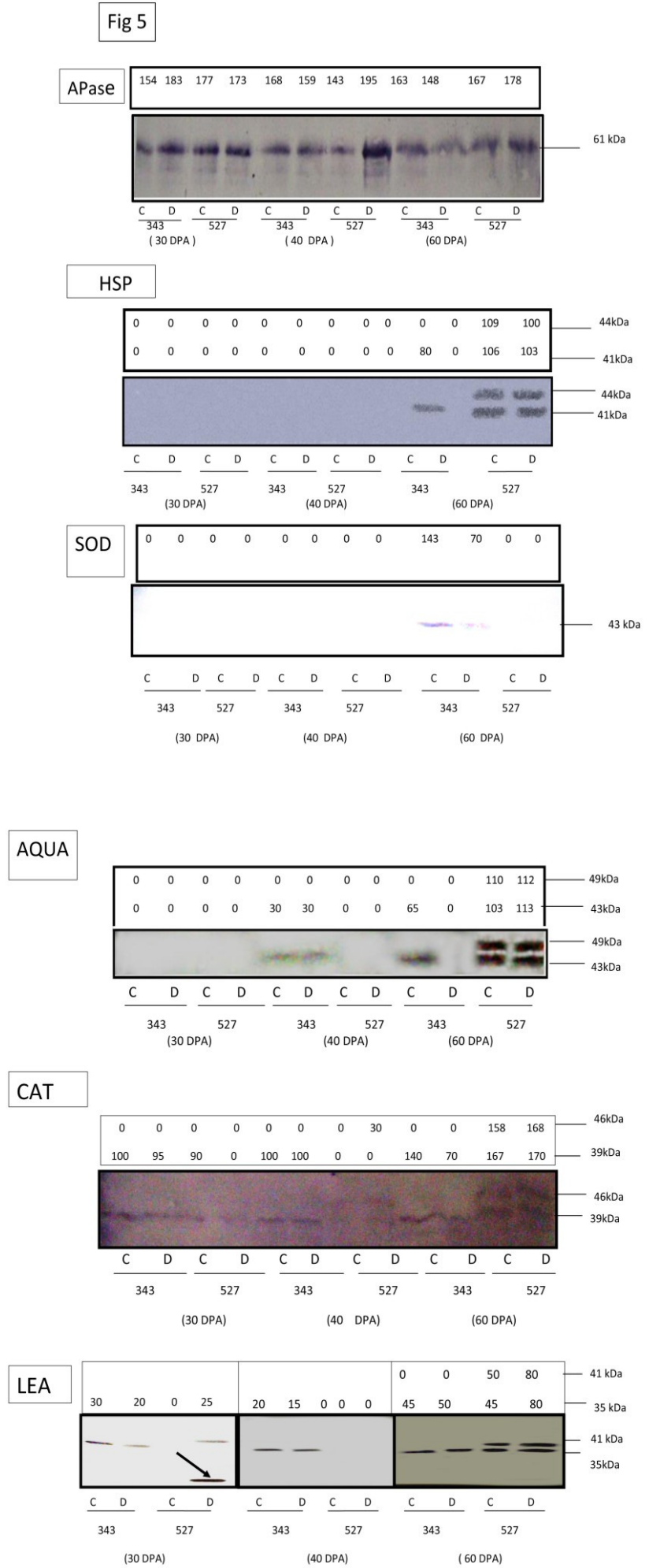

Fig. 5: Immuno-blot analysis of boiling soluble proteins in seeds of drought tolerant ('PBW 527') and drought sensitive ('PBW 343') cultivars of $T$. aestivum at three different stages (30, 40 and 60 DPA) under control (C) and drought (D) conditions. Numerical values as shown in the top of panels indicates relative band intensities which were determined using Gel visualisation, Documentation and Analysis system (BioRad,USA). Arrow shows the presence of differential band
'PBW 527', the expression of BsHSP41 remains unchanged at 60 DPA under drought conditions. Contrary to this, in the susceptible cv. 'PBW 343', the expression of BsHSP41 decreased to nil level. No BsHSP41 was detected in both the cultivars under control and stress conditions at 30 and 40 DPA. Notably, only in drought tolerant cv. 'PBW 527', one immune-reactive band ( 44 kDa) was exclusively detected under both control and drought conditions.

\section{Changes in BsSOD}

Immuno-blot analysis in shoots using SOD antiserum detected a sharp band of $66 \mathrm{kDa}$ (BsSOD66) at $57 \mathrm{DPS}$ only in the cv. 'PBW 527' under drought but not in the control conditions (Fig. 4). On the other hand, in cv. 'PBW 343', BsSOD66 was not responsive either under control or drought conditions. Immuno-blot analysis of the seed samples revealed the presence of an exclusive band of $\mathrm{Mr} 43$ $\mathrm{kDa}$ (BsSOD43) only in the cv. 'PBW 343' at 60 DPA. However, no BsSOD43 was detected in cv. 'PBW 527' at any given stage in seed (Fig. 5).

\section{Changes in BsAqua}

Western blot analysis using antiAqua5 did not recognize any band in shoots, however, in seeds, a prominent protein band of $\mathrm{Mr} 43$ (BsAQP43) at $60 \mathrm{DPA}$ in both the cultivars under control conditions was detected (Fig. 5). However, under drought conditions, at 60 DPA, in cv. 'PBW 527', the expression of BsAQP43 increased slightly. On the contrary, the expression of BsAQP43 decreased to nil level in the susceptible cv. 'PBW 343', thus indicating cultivar specific expression of the proteins. However, no BsAQP43 was detected in both the cultivars under control and stress conditions at 30 DPA. At 40 DPA, only in cv. 'PBW 343', barely detectable band of BsAQP43 in equal amount was observed under both the conditions. Notably, only in drought tolerant cv. 'PBW 527', one immune-reactive band $(\sim 49 \mathrm{kDa})$ was exclusively detected under both control and drought conditions in similar amounts.

\section{Changes in BsCAT}

Immunoblot analysis did not detect any immunereactive boiling soluble protein band in the shoots but revealed the presence of one boiling soluble Catalase (BsCAT39) which was differentially regulated at various stages of seed development in the tolerant and susceptible cultivars of wheat. BsCAT39 expressed constitutively in cv. 'PBW 343' at all the stages, with the expression decreasing considerably under stress at 60 DPA while at 30 and 40 DPA, the expression remain unchanged after drought stress. On the other hand, at 60 DPA in cv. 'PBW 527', BsCAT39 remained unchanged under stress conditions but at 30 DPA, BsCAT39 decreased considerably. Interestingly, only in cv. 'PBW 527' at 60 DPA, an exclusive differential band $(\sim 46 \mathrm{kDa})$ was detected under control as well as stress conditions, whose expression increased slightly after drought treatment (Fig. 5).

\section{Changes in the BsLEA}

Western blot analysis using LEA antiserum did not recognize any band in the shoots. Notably, in seeds, at 30 DPA, a remarkable increase in the BsLEA35 was observed 
230

in the tolerant cv. 'PBW 527' under drought stress conditions (Fig. 5). Besides this, one differential band of $\sim \mathrm{Mr} 20 \mathrm{kDa}$ (marked by arrow) was detected in the tolerant cultivar but not in the susceptible cv. 'PBW 343' (Fig. 5). At $40 \mathrm{DPA}$, a single exclusive protein band of $\mathrm{Mr}$ $35 \mathrm{kDa}$ (BsLEA35) was detected only in the cv. 'PBW 343' which decreased slightly in response to drought conditions. No protein band antigenically similar to BsLEA35 was detected in cv. 'PBW 527' at this stage. At 60 DPA, a prominent band of $\mathrm{Mr} 35 \mathrm{kDa}$ (BsLEA35) was identified in both the cultivars under control as well as stress conditions. However, under drought conditions, in cv. 'PBW 527', a drastic increase in BsLEA35 expression was observed whereas in cv. 'PBW 343', no significant change in expression of BsLEA35 was observed. Remarkably, in cv. 'PBW 527', a differential band of $41 \mathrm{kDa}$ was detected under control as well as stress conditions and imposition of drought resulted in a dramatic increase in the BsLEA41 expression.

\section{Kinetic studies on the regulation of BSPs in seeds}

Kinetics of drought stress-induced changes in RWC and associated BSPs were studied at $3^{\text {rd }}, 6^{\text {th }}$ and $10^{\text {th }}$ day of drought stress treatment. The post-stress kinetic was studied by relieving the drought stress after the $10^{\text {th }}$ day of stress followed by harvesting of samples at $1^{\text {st }}, 2^{\text {nd }}$ and $3^{\text {rd }}$ day. Kinetic studies revealed that in cv. 'PBW 343', there was a significant decrease in RWC at $3^{\text {rd }}$ and $6^{\text {th }}$ day of stress imposition whereas no substantial change was observed at $10^{\text {th }}$ day as shown in the Fig. 6A. On the contrary, in the tolerant cv. 'PBW 527', significant difference in RWC under drought stress was seen only at $3^{\text {rd }}$ day (Fig. 6A). Conversely, no change in RWC was observed at $6^{\text {th }}$ and $10^{\text {th }}$ day of stress. Upon re-watering, the stressed plants regained RWC values equivalent to control plants in both the cultivars just after $1^{\text {st }}$ day of re-watering and remained constant thereafter.

Immuno-blot analysis using antiserum against APase depicted variable trend in both the cultivars. At $3^{\text {rd }}$ day of time course study, nil expression was observed in the cv. 'PBW 527' under control and drought conditions but in cv. 'PBW 343', BsAPase68 expression was detected which was similar under both the conditions. As the duration of drought stress increased to $6^{\text {th }}$ day, in cv. 'PBW 527', there was a drastic up-regulation of BsAPase68 expression. Contrary to this, in cv. 'PBW 343', expression of BsAPase was decreased marginally in response to stress. Upon severe stress $\left(10^{\text {th }}\right.$ day), BsAPase68 expression declined to undetectable levels in both the cultivars under both the conditions (Fig. 6B). Interestingly, upon relieving the stress after $10^{\text {th }}$ day of drought, in tolerant cv. 'PBW 527', there was detection of BsAPase 68 at 1 and 2 PSH following which it declined to nil by $3 \mathrm{PSH}$. In the susceptible cv. 'PBW 343', no BsAPase68 was detected upon re-watering the stressed plants for three consecutive days.

\footnotetext{
Developmental regulation of boiling soluble proteins (BSPs) in seeds

Grain water content in both the cultivars decreased gradually from 90 to $40 \%$ with time as shown in the Fig. $\$ A$. The grains of cv. 'PBW 343' had decline in the water content with no change in the DW (Fig. 7B). On the other
}

hand, in cv. 'PBW 527', continuous decline in grain water content from 30 to 60 DPA was accompanied by dry matter accumulation as shown in Fig. 7B. The SDS-PAGE profile of the boiling soluble proteins in seeds of drought tolerant and drought susceptible cultivars depicted that there was an enhanced expression of the boiling soluble proteins later towards maturity (data not shown). Various high mol wt (HMW) and Medium mol wt (MMW) boiling soluble protein bands were detected in both the cultivars at 60 DPA. Further, quantitative analysis after immune-blot studies using different antiserums is shown in the Fig. 7 C,D. In both the cultivars, a sharp linear increase in the expression of various BSPs like HSP, SOD, AQUA, CAT and LEA was observed from 30 to 60 DPA.
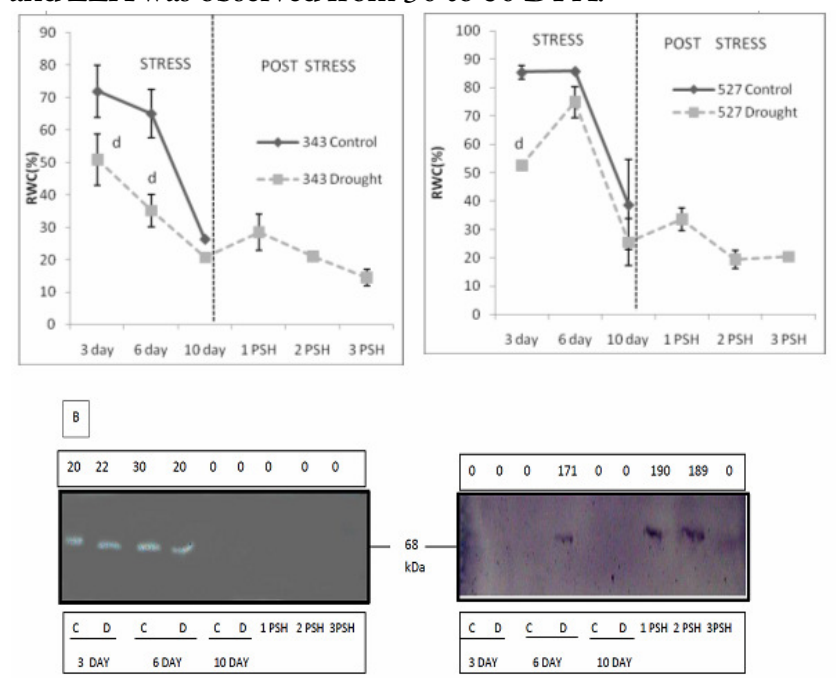

Fig. 6 : Kinetics of RWC (A) and Immuno-blot analysis of boiling soluble proteins (B) using antiserum against APase in seeds of drought tolerant ('PBW 527') and drought sensitive ('PBW 343') cultivars of $T$. aestivum under control and drought stress conditions harvested at different time intervals. Numerical values as shown in the top of panels indicates relative band intensities which were determined using Gel visualisation, Documentation and Analysis system (Bio-Rad, USA). PSH: Post Stress Harvest, C: control, D: drought stress

\section{Discussion}

In the present study, effect of drought stress on BSPs and related biochemical / physiological changes were investigated in drought tolerant and susceptible cultivars of wheat at different developmental stages. Changes in the physiological parameters like chlorophyll content and RWC were recorded. These parameters point towards the tolerance ability of plants under various stress conditions. The Chlorophyll content of leaf is an indicator of photosynthetic capacity of plant tissues and the decline in its activity is the first indicator of leaf senescence in plants subjected to drought (Gregerson and Holm, 2007). The total chlorophyll content and its different fractions, as observed at 30 and 57 DPS, was affected in the sensitive cv. 'PBW 343' and decreased to significant levels under drought stress while the total chlorophyll and its fractions in the tolerant cv. 'PBW 527' remain unaffected under drought at 30 and 57 DPS (Fig 1). 


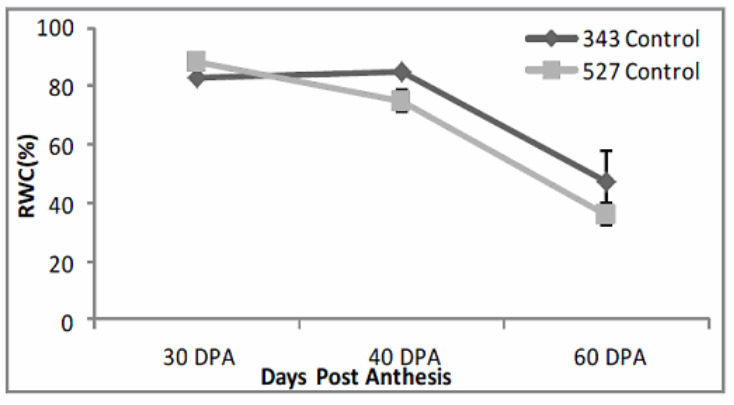

A)

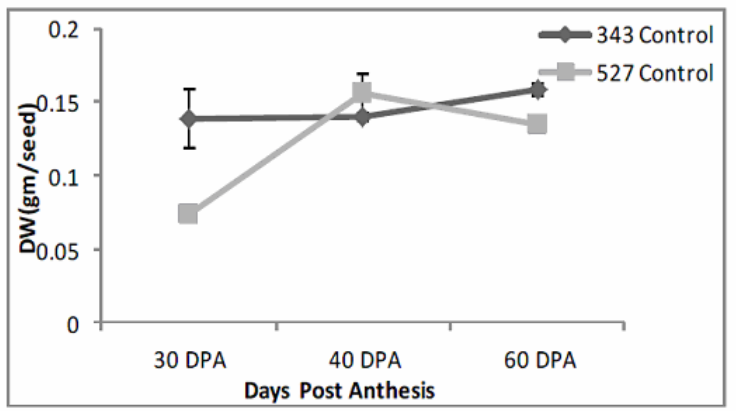

B)

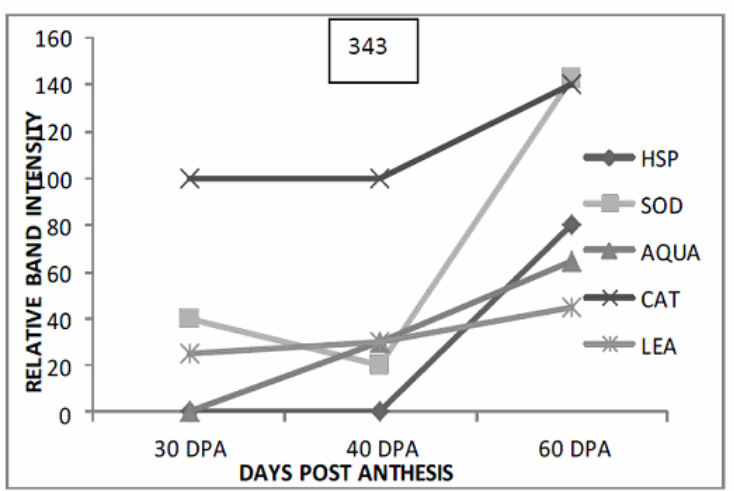

C)

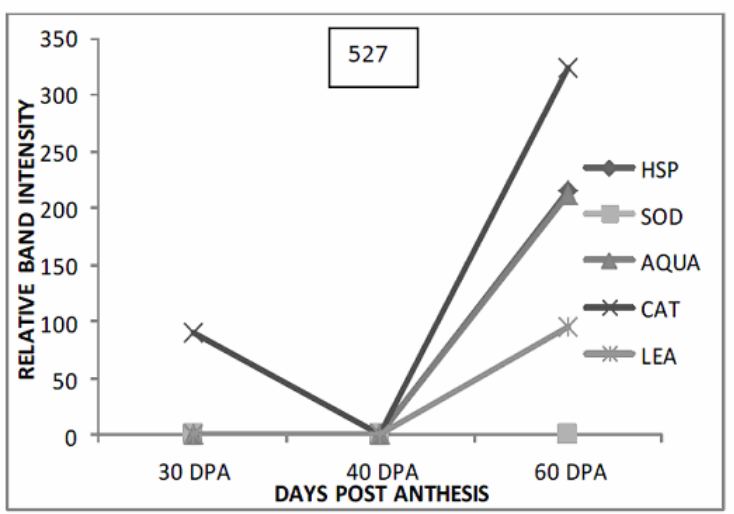

Fig. 7: Developmental regulation of RWC (A), DW (B) and Quantitative analysis of developmentally regulated immunereactive boiling soluble proteins in seeds of drought sensitive cv. 'PBW 343' (D) and drought tolerant cv. 'PBW 527' (E) cultivars of $T$. aestivum harvested at three different stages: 30 DPA, 40 DPA, 60 DPA under control and drought conditions. Quantitative analysis was carried by measuring the relative band intensities of respective immune-reactive BSPs using Gel visualisation, Documentation and Analysis system (Bio-Rad, USA). DPA: Days Post Anthesis
Munne-Bosch et al. (2001) also reported that symptoms of senescence, when exposed to drought stress, were more in drought susceptible species. Same authors also demonstrated that drought-stressed senescing leaves showed enhanced lipid per-oxidation, chlorophyll loss, reduced photosynthetic activity and strong reductions of membrane-bound chloroplast antioxidant defence, which indicates oxidative stress in chloroplasts. Decreased or unchanged chlorophyll content, as observed in this study, for the tolerant cv. 'PBW 527', has also been reported earlier in other plant species under drought stress depending upon the duration and the severity of the stress (Schelmmer et al., 2005). At 90 DPS, the total chlorophyll and its different fractions decreased considerably in both the cultivars under drought conditions. A decrease in chlorophyll content at different developmental stages may be attributed to the production of Reactive Oxygen Species (ROS) like $\mathrm{O}_{2}^{-}$and $\mathrm{H}_{2} \mathrm{O}_{2}$ causing lipid peroxidation and consequently chlorophyll destruction (Foyer et al., 1994). From the findings of this study, it can be speculated that the chlorophyll contents were regulated differentially from 30 to 90 DPS by drought stress in a genotype dependent manner.

Relative Water Content (RWC) is of great importance in assessing the response of the plant to water stress. Shoot RWC remain unchanged at all the three stages in the tolerant cultivar 'PBW 527' under stress while in the other cultivar 'PBW 343', a sharp decline was observed at 57 DPS under stress conditions (Fig. 2A,B). Differences in drought tolerance between tolerant and susceptible cultivars can be attributed to the difference in dehydration tolerance. Earlier studies by Ristic et al. (1991) in Zea mays, have also observed that the decrease in the tissue water content was less prominent in tolerant cultivar as compared to the sensitive cultivar under stress conditions and henceforth have a greater ability to avoid dehydration than the sensitive cultivar under stress conditions. We have also noticed similar observations, as upon imposition of the drought stress, a significant decrease in RWC was observed in the cv. 'PBW 343' at 57 DPS while in the tolerant cv. 'PBW 527', it remained unaffected. Taken together, it can be argued that this kind of response in cv. 'PBW 527' may be a sort of protection given by osmolytes under water stress. As indicated earlier, Pinheiro et al. (2004) also observed no change in tissue water content upon drought stress. Same authors also observed that this response is associated with protection given by assimilates mainly fructose, glucose and sucrose whose levels doubles under water deficits.

\section{Changes in the expression of BSPs in seeds and shoots}

Alteration in the protein expression including either the induction or repression of the gene products in response to drought conditions is considered as an inbuilt capacity of the plants to respond and survive under stress (Ingram and Bartels 1996; Atkinson et al., 2013; Prasch and Sonnewald 2013). The accumulation of the different proteins is associated with the development, stabilization of the membranes, enzyme complexes and macromolecules under control and adverse environmental conditions. (Shinozaki and Yamaguchi-Shinozaki, 2007). The SDS- PAGE profile of the shoots and seeds at various stages depicted that after boiling treatment, many protein bands disappeared and a 
232

few barely detectable protein bands were seen at all the stages, thereby indicating boiling soluble nature of the existing peptides. As seen from the SDS - PAGE profile of the seeds and shoots, seeds at all the three stages exhibit a more number of high mol wt and low mol wt boiling soluble proteins (Fig. 3). This is in agreement with the previous report that extensive protein synthesis is known to occur in the reproductive plant structures (Duck et al.,1989). Based on these observations, it is conceivable that in seeds, BSPs were critical for protection of cellular components during seed development. In order to gain further insight into the biochemical role of BSPs, we studied effect of drought stress on the expression of some BSPs like HSP90, APase, LEA, Aquaporin, CAT, SOD in drought tolerant cv. 'PBW 527' and susceptible cv. 'PBW 343' of wheat by western blotting.

Acid phosphatases are known to be regulated by developmental as well as environmental factors (Vance et al., 2003). Several physiological roles like seed dormancy, embryo germination and cell wall regeneration have been assigned to acid phosphatases but the biochemical roles of boiling soluble acid phosphatases under drought stress is still ambiguous. Western blot analysis detected BsAPase in shoots and seeds of both the cultivars under control conditions, which indicates that both the lines have genes that encodes protein of this mass. However, the two cultivars differ with respect to the synthesis of this protein under drought. Differences in the accumulation of BsAPase between the two cultivars suggest that the tolerance is conferred by genetically encoded mechanisms. At vegetative phase, the presence of BsAPase 66 at 57 DPS under control conditions in both the cultivars and a decline under drought conditions in both the cultivars indicates probable ROS induced injury to the cell membrane (Xu et al., 1994). Further efforts are needed to understand the details of these mechanisms. In case of seeds, the increase in the BsAPase61 expression in the tolerant cv. 'PBW 527' at 40 and 60 DPA under stress indicates that in tolerant cv. 'PBW 527', BsAPase61 might be playing a significant role in the maintenance of orthophosphate $(\mathrm{Pi})$ levels in the seeds under stress (Fig. 5). Enhanced BsAPase61 expression in cv. 'PBW 527' may be due to the fact that under stressful conditions, the delivery of phosphate is impaired, thus resulting in the activation of the cellular phosphatases that release soluble phosphate from its insoluble compounds inside or outside of the cells thereby modulating osmotic adjustment by a free phosphate uptake mechanism. Olmos and Hellin (1997) also reported that acid phosphatases are believed to act under water and salt stress by maintaining certain levels of inorganic phosphate which can be cotransported along with $\mathrm{H}^{+}$along a gradient of proton motive force. The higher expression of BsAPase 61 in the drought tolerant cv. 'PBW 527' is suggestion of its global role in enhancing Pi availability and possibly recycling of the organic Pi compounds.

Heat Shock Proteins (HSPs) are a set of evolutionary conserved, homologous proteins whose expression is induced by heat shock and variety of stresses like temperature extremes, water deficit etc (Wang et al., 2004). HSPs are classified into five major groups - HSP 100, HSP 90, HSP 70, HSP 60 and small HSPs based on their molecular mass (Wang et al., 2004). Out of these, HSP 90 is one of the most abundant cytosolic proteins in eukaryotes accounting to $1 \%$ of the soluble protein even in the absence of stress (Jovanovic et al., 2011). Besides, being stress responsive, these proteins function as molecular chaperones thereby holding denatured proteins in a folding competent state for subsequent refolding by a chaperone system and also prevent irreversible aggregation during refolding (Wang et al., 2004). Tissue specific expression of the BsHSPs were observed using anti HSP90 monoclonal antibody since the expression was only observed in the seeds and not in the shoots. In seeds, BsHSPs were detected only at $60 \mathrm{DPA}$ and not at 30 and $40 \mathrm{DPA}$, thereby implying that the expression of the BsHSPs were development dependent. Western blot analysis using anti- HSP90 antibody in seeds gave two sharp bands ( 41 and $44 \mathrm{kDa}$ ) at $60 \mathrm{DPA}$. BsHSP 41 was expressed in both the cultivars under control at 60 DPA and there was a differential expression of BsHSP41 at 60 DPA under drought conditions in both the cultivars which indicates cultivar specific expression of the proteins ( Fig. 5). There was a presence of the additional band of BsHSP44 at 60 DPA in the tolerant cultivar under both the control and drought conditions. Accumulating evidences have shown that high mol wt HSPs are abundant components of most of the unstressed cells but their induction under drought conditions represent increased synthesis of one or more of the HSP isoforms. Krishna et al. (1995) also reported that in wheat, unique set of HSPs are synthesized which are absent in the thermal sensitive cultivar. The presence of BsHSP44 under stress conditions at 60 DPA in the tolerant cv. 'PBW 527' prompted its consideration as an essential factor of the adaptation of this cultivar under drought conditions.

It was reported earlier that water deficit stress often results in the over production of the_Reactive Oxygen Species (ROS) which in turn lead to oxidative stress in the cells (Apel and Hirt 2004). ROS damages proteins either by amino acid modifications or increased susceptibility to proteolysis. Superoxide dismutase (SOD) (EC.1.1.15.1.1) is the first line of defence against the deleterious effects of ROS (Apel and Hirt 2004). SOD are a group of multimeric metalloenzymes that catalyzes the dismutation of superoxide free radicals to dioxygen and $\mathrm{H}_{2} \mathrm{O}_{2}$ which is subsequently reduced to $\mathrm{H}_{2} \mathrm{O}$ by Guaiacol peroxidase in cytosol or by catalase in peroxisomes. In shoots, there was an expression of the BsSOD66 in the cv. 'PBW 527' only under stress at 57 DPS (Fig. 4). The nil expression of the BsSOD66 in the cv. 'PBW 343' under control and drought conditions again indicates the cultivar dependent expression of the BsSOD66. Earlier, similar observations have been reported by Badawi et al. (2007) who found that the heat tolerant genotype showed higher SOD expression than the heat sensitive cultivars under high temperature conditions. In addition, in our study, we investigated a significant drought-induced increase in total reducing sugar content in cv. 'PBW 527' (data not shown). In the previous studies, Goyal et al. (2005) have observed that combination of LEA proteins and non-reducing sugars offers better protection against protein aggregation after water stress than each component alone. Thus, it can be speculated that like LEA, BsSOD66 might act synergistically with other protective compounds in the dry state. By virtue of having substantial BsSOD66 expression, it is plausible the tolerant cv. 'PBW 
$527^{\prime}$ has better antioxidant capacity and higher tolerance to drought stress than the susceptible cv. 'PBW 343'. Thus, we can say that differences in boiling soluble SOD expression may be a useful screening criterion for drought tolerance.

Intra- and inter-cellular water movement across the membranes is facilitated and regulated by the multifunctional proteins called as aquaporins which constitutes a large and highly divergent protein family in plants (Danielson and Johanson, 2008). The different responses of the AQP expression (up/down regulation or no change) to water stress suggest that AQP isoforms can be divided into different groups which contribute differently to water transport and regulation, with some being stress responsive. Several diverse roles of aquaporins have been reported earlier, for instance, Henzler and Steudle (2004) demonstrated the role of aquaporin gene in controlling rapid and active movement. Recently, using immunological and translational fusion approaches, Uehlein et al. (2008) have shown that $\mathrm{NeAQP1}$ play a key role in $\mathrm{CO}_{2}$ assimilation in the chloroplast membrane. In addition, possible roles of aquaporins in ROS induced stress signalling has also been well documented in Arabidopsis (Jang et al., 2012). On the contrary, negative effects of drought stress on aquaporin gene expression have also been published ( $\mathrm{Xu}$ et al., 2013). Although, the discovery of these proteins and detailed studies of their function brought an upheaval in the understanding of the plant water relations, but still the relationship between aquaporins at boiling level and drought avoidance remains elusive. As observed in our study, the expression of the BsAQP was stage, cultivar and tissue dependent like BsHSP. The BsAQP expression was only observed in the seeds and not in the shoots which point towards the tissue dependent expression of the BsAQP. In the seeds, BsAQP was detected only at 40 and 60 DPA in both the cultivars, thereby revealing the stage/development dependent expression for the BsAQP (Fig. 5). At 60 DPA, under drought stress, increase in BsAQP43 expression in cv. 'PBW $527^{\prime}$ and decrease in its expression cv. 'PBW 343' implies the cultivar dependent expression. Previously, Lian et al. (2004) studies reported sharp increase in the expression of the water channel protein RWC3 in the upland (drought resistant) rice and decrease in the lowland (drought susceptible) rice under drought stress. It can be hypothesized that the BsAQP43, like RWC3, plays a role in drought avoidance in the tolerant cultivar by adjusting the water movement across the plasma membrane, absorbing remaining water and by maintaining cell turgor.

During water stress, the enhanced level of $\mathrm{H}_{2} \mathrm{O}_{2}$ has been reported inside the cells which is a by-product of antioxidant action of SOD, photorespiration and $\beta$ oxidation of fatty acids and toxic to cells (Apel and Hirt, 2004). Therefore, it is of prime importance that it should be rapidly scavenged by the antioxidant enzyme system and this is carried out by catalase (E.C1.11.1.6), which is a universally present oxidoreductase in peroxisomes and glyoxisomes. Catalase removes $\mathrm{H}_{2} \mathrm{O}_{2}$ by breaking it down to $\mathrm{H}_{2} \mathrm{O}$ and $\mathrm{O}_{2}$. At seed stage, there was a differential expression (declined/unchanged) of the BsCAT39 in both the cultivars at various stages of growth (Fig. 5). The reduction of BsCAT39 protein expression in both the cultivars is supposedly due to the inhibition of enzyme synthesis, inactivation of enzyme protein due to ROS (Feieraband et al., 1986) or change in the assembly of enzyme subunits under stress conditions. It may also be associated with the degradation caused by induced peroxisomal proteases or may be due to the photoinactivation of the enzyme. BsCAT46 was solely expressed in the tolerant $\mathrm{cv}$. 527 at 60 DPA under both the conditions, with a slight increase in the expression under drought. Thus, it can be speculated that the increased BsCAT46 expression under drought could be an indication of elevated ROS since the amount of catalase is directly proportional to the oxidative state of the cells (Apel and Hurt , 2004).

LEA, a diverse group of distinct proteins encoded by small multigene families were characterized first in cotton embryos. LEA proteins have been classified into 6 groups based on their sequence similarities (Ingram and Bartels, 1996). These proteins are synthesized in the maturing seeds at the onset of desiccation and some proteins also accumulate in the vegetative tissues exposed to water deficit and stress conditions. They have basal levels of expression but are induced to high levels during various kinds of stresses including drought (Ingram and Bartels 1996; Barrera-Figueroa et al., 2007). Various transgenic and genetic studies have also shown the relationship between the accumulation of some LEA proteins and enhanced stress tolerance (Hara et al., 2003). Besides this, LEA proteins function as molecular chaperones protecting and stabilizing proteins (Close, 1996). They also act as stabilizing solvents to prevent crystallization of cellular components and also help in sequestration and scavenging of ions in the cytoplasm of the stressed cells . The results of the present study indicate that the BsLEAs begin to express at earlier stages of growth under control and stress conditions. The earlier detection of LEA protein (BsLEA35) at 30 DPA under drought stress in the tolerant cultivar indicates that it might have a key role in the developing seeds during water stress. Han et al. (1997) also reported the expression of 25 $\mathrm{kDa}$ LEA in Ricinus Communis seeds during early- to midseed development stages. At 60 DPA, the expression of the BsLEA35 increased tremendously under drought in the cv. 'PBW 527' while on the other hand, in the cv. 'PBW 343', the expression of BsLEA35 remain unaffected upon imposition of the stress (Fig. 5). A dramatic increase in the expression of a differential band of BsLEA41 expression was observed in the tolerant cultivar 'PBW 527'. Earlier, Han et al. (1997) also reported the expression of some differential LEA bands of $\mathrm{Mr} 28-30$ and $41 \mathrm{kDa}$ at physiological maturity of seeds in castor bean. Considering the expression patterns of the BsLEA proteins at different stages, it can be suggested that LEA proteins in the tolerant cv. 'PBW 527' can protect specific cellular structures or ameliorate the effects of drought stress by maintaining a minimum cellular requirement (Ingram and Bartels, 1996).

\section{Kinetic studies on the regulation of BSPs}

The tolerance to various abiotic stress factors in crops is based upon efficient defence and repair mechanisms not only in response to stress but also during stress relief (Charron and Quatrano, 2009). So, to gain an insight into the role of BsAPase under different drought durations followed by subsequent relieval of stress, immune-blot 
234

analysis using antiserum against APase was carried out for the kinetic study, as this was the best expressed antiserum at different developmental stages of seed. From the results of the western blot analysis, it was observed that under severe stress conditions (10 days of drought imposition), no BsAPase68 expression was observed in both cultivars, indicating severe damage to biochemical machinery. However, at $6^{\text {th }}$ day of drought, a remarkable induced expression of BsAPase 68 was observed in tolerant cv. 'PBW 527', whereas a marginal decrease was observed in cv. 'PBW 343'. Such modulations in the expression have been reported for several stress inducible genes. For example, transient expression of cyclophilin ( $\mathrm{CyP})$ genes has been reported in response to various kinds of stresses like salt, cold, heat, metal and wound in fava bean (Marivet et al.,1992), to heat stress in Solanum tuberosum (Godoy et al., 2000) and to low temperature, drought, salicyclic acid and pathogen attack in Solanum commersonii (Leonardo et al., 1998). Various proteins in plants have been suggested to be important not only during stress conditions but also during plant recovery from stress (Waters et al., 1996). This prompted us to analyse the expression of BsAPase upon relief from drought stress in both the cultivars so as to gain further an insight into the physiological role of this protein. During post-stress study, relatively, high BsAPase68 expression was detected during the first two recovery days in the tolerant cultivar 'PBW 527', suggesting a possible role for this protein in the recovery stage. No BsAPase68 expression was observed in drought sensitive cv. 'PBW 343' during recovery period. BsAPase68 expression after the stress was relieved in the cv. 'PBW 527', indicate that they participate in the repair of cellular damage and also provide an adaptative tolerance in the event of future stress. Our results were consistent with the earlier study by Almoguero et al. (1993) in which they have observed that the levels of accumulated low molecular weight HSPs in sunflower plants remained high during stress recovery. Further, mutant analysis by Ruibal et al. (2013) also added evidence for the role of proteins during the recovery of Physcomitrella patens plants from various abiotic stresses. Same authors have observed that knockout mutants of two PpHsp16.4 genes lead to impaired or delayed recovery of plants under various abiotic stresses like salt, osmotic and heat stress, thereby implicating the role of this gene and its translation product in the recovery process. Our study emphasizes the importance of cellular mechanisms that protects protein integrity and enable damage repair upon stress relief.

\section{Developmental Studies}

To examine the role of BSPs in seed development, BSPs regulation was studied in seeds at different developmental stages under well water irrigated conditions. Seeds are developmentally programmed to go through a series of several recognizable developmental stages coupled with several physiological changes like gain in DW and loss in water content during their growth and development. We have also noticed similar changes in RWC and DW. During drying, seed passes through an array of hydration ranges that also necessitate protection against drought. Earlier biochemical studies have indicated that seed development is accompanied by a buildup of desiccation tolerance in which most of the seeds lose their water towards maturity and desiccate (Raynal et al., 1989). Seeds have remarkable desiccation tolerance due to their ability to survive extreme water loss during final maturation state of development (late embryogenesis). Molecular studies have revealed that the desiccation period near seed maturity stage is not simply characterized by the passive loss of water but is also marked by the expression of number of genes and synthesis of new proteins (Boudet et al., 2006), which helps the seed to tolerate extreme desiccation periods.

Our results as observed in this study are in agreement with previous reports because quantitative analysis revealed that expression of many boiling soluble proteins (APase, SOD, CAT, HSP, AQUA, LEA) were up-regulated in both the cultivars towards maturity (Fig. 7). The developmental specific expression patterns reflect the biochemical role of the different boiling soluble proteins (BSPs) towards maturity. Thus, it can be argued that in developing seeds, the role of boiling soluble proteins might be similar as in drought tolerant vegetative tissues. Accumulating evidences have shown that like LEAs, some of the proteins (SOD, AQUA, CAT) accumulating at maturity are directly involved in water stress/desiccation tolerance (Boudet et al., 2006).

Based upon these observations, it can be postulated that to cope up with the physical and biochemical challenges accompanying the desiccation process, seeds are endowed with an array of protective mechanisms that act synergistically. Several earlier proteomic studies have shown that many proteins like LEA, HSPs, SOD, POD, CAT, other antioxidants, proteinase inhibitors and a large of set of proteins with unknown functions accumulated at this stage (Bray, 2004). Taken together, it is conceivable that protein accumulation profiles as observed in our study, provides additional evidence supporting a role of these boiling soluble proteins in protection of cells during desiccation induced damage at low water content. The accumulation of the various boiling soluble proteins in the developing seeds can thus, be used as an indicator for determining seed maturity.

\section{Conclusions}

From the results of the present findings, we can conclude that diverse array of the boiling soluble proteins accumulated under drought conditions at different developmental stages in both the cultivars. These proteins were hydrophilins based on the boiling stability. Enhanced expression of BsAPase, BsLEA, BsAQPs, BsHSPs, BsCAT was observed in drought tolerant cv. 'PBW 527' under drought conditions, indicating their role in drought stress adaptation. Further, the presence of more differential (BsHSP44 and BsAQUA49) protein bands in drought tolerant cv. 'PBW 527' with respect to drought susceptible cv. 'PBW 343' under drought conditions might be the reason for higher drought stress tolerance. From the results of the kinetic study, it can be concluded that the tolerant cv. 'PBW 527' have better capacity to overcome the damage resulting from the imposition of the severe drought stress and hence is a better cultivar based upon the expression of BsAPase68 during the post stress period. Thus, the 
detection of BsAPase 68 during the recovery periods can be used as a selection criterion for the drought tolerant cultivars. Similarities in the conditions under which these different boiling soluble proteins are expressed together with their hydrophilic character may underlie a common function for at least a subset of these proteins, remarkably in ameliorating the injurious effects of cellular dehydration. An additional possibility is that some of the boiling soluble proteins can provide regulatory functions directed towards particular enzymes or protein complexes under low water availability. Expression analysis of the boiling soluble proteins in drought tolerant and susceptible cultivars of Triticum aestivum, as evident in our study, could reveal the potential of these proteins as biochemical marker in breeding programmes for making drought tolerant high yielding crops and can suggest possible targets for the enhancement of drought tolerance in crops by genetic engineering.

\section{Acknowledgements}

We would like to thank UGC, Govt. of India for providing financial assistance for the present study. We are also grateful to Dr. Carrol P. Vance, Dept of Agronomy and Plant Genetics, University of Minnesota, St. Paul, MN55108, USA for the gift of lupin APase antiserum. We also thank Dr. AAC Robles, Institute of Biotechnology, Universidad Nacional Autonoma De Mexico, Mexico for providing PvLEA antiserum. We thank Dr. Pawan Kumar Malhotra for providing seeds of two different cultivars of wheat. GR want to thank ICMR for fellowship.

\section{References}

Almoguero C, Coca MA, Jordano J (1993). Tissue specific expression of sunflower heat shock proteins in response to water stress. Plant J 4(6):947-958.

Apel K, Hirt H (2004). Reactive oxygen species: Metabolism, oxidative Stress and signal transduction. Annu Rev Plant Biol 55:373-99.

Arnon DI (1949). Copper enzymes in isolated chloroplasts, polyphenoxidase in Beta vulgaris. Plant Physiol 24:1-15.

Atkinson NJ, Lilley CJ, Urwin PE (2013). Identification of Genes Involved in the Response of Arabidopsis to Simultaneous Biotic and Abiotic Stresses. Plant Physiol 162(4):2028-2041.

Badawi GH, Tahir ISA, Nakata N, Tanaka K (2007). Induction of some antioxidant enzymes in selected wheat genotypes. Afr Crop Sci Conf Proc 8:841-848.

Barrera-Figueroa B, Pena Castro J, Acosta-Gallegos JA, Ruiz Medrano R, Xoconostle Cazares B (2007). Isolation of dehydration responsive genes in a drought tolerant common bean cultivar and expression of group 3 late embryogenesis abundant mRNA in tolerant and susceptible cultivars of bean. Funct Plant Biol 34:368-381.

Boudet J, Buitink J, Hoekstra FA, Rogniaux H, Larre C, Satour P, Leprince O (2006). Comparative analysis of the heat stable proteome of radicles of Medicago truncatula seeds during germination identifies late embryogenesis abundant proteins associated with desiccation tolerance. Plant Physiol 140:14181436.

Bray EA (2004). Genes commonly regulated by water-deficit stress in Arabidopsis thaliana. J Exp Bot 55(407):2331-2341.

Charron AJ, Quatrano RS (2009). Between a rock and a dry place: the water stressed moss. Mol Plant 2:478-486.

Chaves MM, Maroco JP, Pereira JS (2003). Understanding plant responses to drought from genes to the whole plant. Funct Plant Biol 30:239-264.

Close TJ (1996). Dehydrins: emergence of a biochemical role of a family of plant dehydration proteins. Physiol Plant 9:795-803.

Colmenero-Flores JM, Moreno LP, Smith CE, Covarrubias AA (1999). Pvlea-18, a member of a new late embryogenesis abundant protein family that accumulates during water stress and in the growing regions of well irrigated bean seedlings. Plant Physiol 120(1):93-103.

Danielson JAH, Johanson U (2008).Unexpected complexity of the aquaporin gene family in the moss Physcomitrella patens. BMC Plant Biol 8:45.

Duck N, McCormick S, Winter J (1989). Heat shock proteins hsp70 cognate gene expression in vegetative and reproductive organs of Lycopersicon esculentum. Proc Natl Acad Sci 86(10):3674-3678.

Feieraband J, Engel S (1986). Photoinactivation of catalase in vitro and in leaves. Arch Biochem Biophys 251:567-576.

Foyer CH, Descourvieres P, Kunert KJ (1994). Photo-oxidative stress in plants. Plant Physiol 92:696-717.

Garay-Arroyo A, Colmenero-Flores JM, Garciarrubio A, Covarrubias AA (2000). Highly hydrophilic proteins in prokaryotes and eukaryotes are common during conditions of water deficit. J Biol Chem 275:5668-5674.

Godoy AV, Lazzaro AS, Casalongue CA, Sengundo BS (2000). Expression of a Solanum tuberosum cyclophilin gene is regulated by fungal infection and abiotic stress conditions. Plant Sci 152:123-34.

Goyal K, Walton LJ, Tunnacliffe A (2005). LEA proteins prevent protein aggregation due to water stress. Biochem J 388:151157.

Gregersen PL, Holm PB (2007). Transcriptome analysis of senescence in the flag leaf of wheat (Triticum aestivum L.). Plant Biotechnol J 5(1):192-206.

Han B, Hughes W, Galau GA, Bewley JD, Kermode AR (1997). Changes in the late embryogenesis abundant (lea) messenger RNA and dehydrins during maturation and premature drying of Ricinus communis L. seeds. Planta 201:27-35.

Hara M, Terashima S, Fukaya T, Kuboi T (2003). Enhancement of cold tolerance and inhibition of lipid peroxidation by citrus dehydrin in transgenic tobacco. Planta 217:290-298.

Henzler T, Ye Q, Steudle E (2004). Oxidative gating of water channels (Aquaporins) in Chara by hydroxyl radicals. Plant Cell Environ 27(9):1184-1195.

Ingram J, Bartels D (1996). The molecular basis of dehydration tolerance in plants. Annu Rev Plant Biol 47(1):377-403.

Jang YJ, Rhee JY, Chung GC, Kang H (2012). Aquaporin as a 
membrane transporter of hydrogen peroxide in plant response to stresses. Plant Signal Behav 7(9):1180-1181.

Jovanovic SM, Tucic B, Gordana M (2011). Differential expression of heat shock proteins $\mathrm{Hsp} 70$ and $\mathrm{Hsp} 90$ in vegetative and reproductive tissues of Iris pumila. Acta Physiol. Plant 33(1):233-240.

Krishna P, Sacco M, Cherutti JF, Hill S (1995). Cold induced accumulation of Hsp90 transcripts in Brassica napus. Plant Physiol 107(3):915-923.

Leonardo A, Zepada M, Baudo MM, Palva ET, Heino P (1998). Isolation and characterization of a cDNA corresponding to a stress activated cyclophilin gene in Solanum commersoni. J Expt Bot 49:1451-2.

Lin C, Guo WW, Everson E, Thomashow MF (1990). Cold acclimation in Arabidopsis and wheat. Plant Physiol 94:10781083.

Lian HL, Yu X, Ye Q, Ding X, Kitagawa Y, Kwak SS, Su WA, Tang ZC (2004). The role of Aquaporin RWC3 in drought avoidance in rice. Plant Cell Physiol 45(4): 481-489.

Lowry OH, Rosebrough NJ, Farr AL, Randall RJ (1951). Protein measurement with the Folin phenol reagent. J Biol Chem 193(1): 265-275.

Marivet J,Frendo P,Burkard G (1992). Effects of abiotic stresses on cyclophilin gene expression in maize and bean and sequence analysis of bean cyclophilin cDNA. Plant Sci 84:1718.

Miller GL (1972). Use of DNS reagent for the determination of glucose. Anal Chem 31(3):426-428.

Munne-Bosch S, Jubany-Mari T, Alegre L (2001). Droughtinduced senescence is characterized by a loss of antioxidant defences in chloroplasts. Plant Cell Environ 24:1319-1327.

Neven LG, Haskell DW, Hofig A, Li QB, Guy CL (1993). Characterization of a spinach gene responsive to low temperature and water stress. Plant Mol Biol 21(2):291-305.

Olmos E, Hellin E (1997). Cytochemical localization of ATPase plasma membrane and acid phosphatase by cerium based in a salt-adapted cell line of Pisum sativum. J Exp Bot 48:15291535.

Pelah D, Shoseyov O, Altman A (1995). Characterization of BspA, a major boiling stable water stress responsive protein in aspen (Populus tremula). Tree Physiol 15:673-678.

Pfeiffer WH, Trethowan RM, Van GM, Ortiz MI, Rajaram S (2005). Breeding for abiotic stress tolerance in wheat. In: Ashraf M and Harris PJC (eds). Abiotic Stresses: Plant Resistance through Breeding and Molecular Approaches, The Haworth Press, New York, NY, USA, pp. 401-489.

Pinheiro HA, DaMatta FM, Chaves ARM, Fontes EPB, Loureiro ME (2004). Drought tolerance in relation to protection against oxidative stress in clones of Coffea canephora subjected to long-term drought. Plant Sci 167:1307-1314.

Prasch CM, Sonnewald U (2013). Simultaneous Application of Heat, Drought, and Virus to Arabidopsis Plants Reveals Significant Shifts in Signaling Networks. Plant Physiol. 162(4):1849-1866.

Rakhra G, Sharma AD (2013). Expression of boiling stable proteins (hydrophilins) in response to salt, osmotic, cold, drought and $\mathrm{ABA}$ treatments in drought tolerant and susceptible cultivars of Triticum aestivum. Int J Agric Sci Res 3(4):161-178.

Raynal M, Depigny D, Cooke R, Delseny M (1989). Characterization of a radish nuclear gene expressed during late seed development. Plant Physiol 91:829-836.

Ristic Z, Gillford DJ, Cass DD (1991). Heat shock proteins in two lines of Zea mays L. that differ in drought and heat resistance. Plant Physiol 97:1430-1434.

Ruibal C, Castro A, Carballo V, Szabados L,Vidal S (2013). Recovery from heat, salt and osmotic stress in Physcomitrella patens requires a functional small heat shock protein PpHsp16.4.BMC Plant Biol 13:174.

Sambrook J, Fritsch EF, Maniatis T (1989). Molecular cloning: a laboratory manual (Ed 2). Cold Spring Harbour Laboratory Press New York pp 18.64-18.75.

Schlemmer MR, Francis DD, Shanahan JF, Schepers JS (2005). Remotely measuring chlorophyll content in corn leaves with different nitrogen levels and relative water content. Agron J 97(1):106-112.

Sharma AD, Rakhra G, Mehta A, Mamik S (2014). Accumulation of class III type of boiling stable peroxidases in response to plant growth hormone ABA in Triticum aestivum cultivars. Plant Sci Today 1(1):3-9.

Sharma AD, Rakhra G, Singh J (2012). Expression analysis of BsAPase 14 acid phosphatase, a stress responsive boiling-stable protein from Triticum aestivum. J Crop Sci Biotech 15(1):4145.

Shinozaki K, Yamaguchi SK(2007). Gene networks involved in drought stress response and tolerance. J Exp Bot 58:221-227.

Uehlein N, Otto B, Hanson DT, Fischer M, McDowell N, Kaldenhoff R (2008). Function of Nicotiana tabacum aquaporins as chloroplast gas pores challenges the concept of membrane CO2 permeability. The Plant Cell 20(3):648-657.

Vance CP, Stone UC, Allan DL (2003). Phosphorus acquisition and use: critical adaptations by plants for securing a nonrenewable resource. New Phytol 157(3):423-447.

Wang W, Vinocur B, Shoseyov O, Altman A (2004). Role of plant heat shock proteins and molecular chaperones in the abiotic stress response. Trends Plant Sci 9:244-252.

Waters ER, Lee GJ, Vierling E (1996). Evolution, structure and function of the small heat shock proteins in plants. J Expt Bot 47:325-338.

Xu SC, Shen XY, Gu WL, Dai JY, Wang LZ (1994). Changes of lipid peroxidation, reesterification of phosphatide and ultrastructure of membrane in leaf cells of maize under soil drought condition. Acta Agron Sin 30:564-569.

Xu C, Wang M, Zhou L, Quan T, Xia G (2013). Heterologous expression of the wheat aquaporin Gene TaTIP2; 2 compromises the abiotic stress tolerance of Arabidopsis thaliana. Plos One 8(11):e79618.

Zhu JK (2002). Salt and drought stress signal transduction in plants. Annu Rev Plant Biol 53:247-273. 